\title{
TeChNOlogy, ReSiduals, AND THE NeW THREAT to HollyWOOD SCREENWRITERS
}

\author{
By Kevin Leary \\ Volume XIII - Fall 2012
}

As the video home system (VHS), an enigmatic new medium for the consumption of television and movies, emerged into the market place in the 1980s, film and television writers were excluded from much of the proceeds. Unaware of how lucrative the VHS home movie industry would eventually be, writers failed to perceive the potential residual revenue which could be created. They subsequently did not demand a large enough cut of the pie in contract negotiations, leaving them to a large degree excluded from the proceeds. ${ }^{1}$ Now, with the advent of new technology, another potential, and in some ways more mysterious, cash cow exists. Although the specifics of what could be gained by the screenwriters are still somewhat unknown, there is little doubt that revenue from internet and DVDs will be an important part of the monetized future of rebroadcast media.

As a result of technology, moving from VHS to DVD and now the Internet, the consumption of syndicated media has changed radically. Once relegated to the chasms of cable or after-hours television, re-runs have enjoyed a completely different form of enjoyment over the past decade. Thanks to these new forms of technology, first the DVD and now the internet, the life-span of television shows has been significantly altered. Shows now are given a second life. Whereas "failed shows" like Arrested Development or Family Guy would have forever disappeared in generations past, the advent of the DVD allowed such shows to grow in

\footnotetext{
${ }^{1}$ Writers Strike Is Over, SUN SENTINEL, Mar. 20, 1985, http://articles.sun-sentinel.com/1985-0320/news/8501100926_1_writers-guild-writers-share-chief-writer.
} 
popularity even after they went off-air. ${ }^{2}$ Perhaps in a fitting symmetry, Arrested Development is now being re-launched with a season of new episodes going directly to Netflix. ${ }^{3}$ Movies have similarly enjoyed a longer life-span as evidenced by the re-release of the 1982 Walt Disney film Tron to tie in with the new film. ${ }^{4}$ A film from 1982 is generating new profits in 2012 because of the DVD industry.

It was then somewhat unsurprising that despite uncertainty as to how much the massive expansion of the internet might be worth to television and the movies, writers went on strike in 2007 to claim their right to be compensated for income generated by their intellectual property through the Internet, DVD, and Blu-ray. This strike, which lasted for exactly one hundred days, attracted the attention of millions of Americans whose favorite sitcoms, dramas, and late night comedy shows were put into a forced hiatus. Yet, despite having the nation's ear, the striking Writers Guild of America (WGA) missed a far more insidious threat to the well-being of the members of their union; the industry as a whole is contracting. Almost five years after the beginning of that strike, more has worsened for the members of the WGA than has improved. There is a growing possibility that one of the unintentional effects of the strike was a reduction of opportunities for writers, creating a more competitive marketplace where writers, in need of work, will allow film and television studios to overlook many of their collectively bargained payment duties.

\footnotetext{
${ }^{2}$ Jacob Clifton, How Have DVDs Changed the Lifespan of TV Shows?, HowSTUFFWoRKS (Mar. 11, 2011), http://people.howstuffworks.com/culture-traditions/tv-and-culture/dvds-changed-lifespan-of-tv-shows1.htm. ${ }^{3}$ Jason Gilbert, Netflix On "Arrested Development" Release: Season 4 Episodes Will Be Available All At Once, HufFINGTON POST (Apr. 19, 2012, 10:57 AM), http://www.huffingtonpost.com/2012/04/19/netflix-arresteddevelopment-release-season-4-episodes_n_1437273.html.

${ }^{4}$ Brooks Barnes \& Jenna Wortham, New Strategy for 'Tron' DVD, Media DeCoder Blogs - N.Y. Times (Dec. 19, 2010, 9:37 PM), http://mediadecoder.blogs.nytimes.com/2010/12/19/new-strategy-for-tron$\mathrm{dvd} /$ ? scp=5\&sq=dvd\&st=cse. 


\section{VHS, DVD, And the Internet. The Past, Present, and Future}

In 1985, the WGA went on strike to demand a share of the then burgeoning videocassette market. ${ }^{5}$ VHS was a new and potentially lucrative market, and writers, who were entitled to residuals for their creation as a part of the agreement, demanded a portion of the proceeds. ${ }^{6}$ The agreement was that the writers would receive 1.5 percent of the producers' take. ${ }^{7}$ However, they soon discovered that they were getting a smaller-than-expected amount of money in residuals. ${ }^{8}$ Film companies were using the 1.5 percent figure out of the producers' gross instead of the overall gross. The significant cost of the actual manufacturing of VCRs and cassettes altered the proceeds. ${ }^{9}$ The writers were left with roughly 0.3 percent of total sales - or one fifth of the amount that they had thought had been collectively bargained. ${ }^{10}$ This remained the case even after the cost of producing VHS tapes drastically declined.

Even though the screenwriters began to feel they had been cheated out of what they believed was fair compensation for the use of their intellectual property through the VHS payment arrangement, this same arrangement continues to this day. When DVD supplanted VHS as the medium of choice for film and television, the 1985 agreement moved with it. ${ }^{11}$ Subsequently, just as it was the case with the VHS, writers get 0.3 percent of the money from the sale of DVDs. ${ }^{12}$ Thus, for every $\$ 10$ DVD that is purchased, the writer or writers who authored

\footnotetext{
${ }^{5}$ Writers Strike Is Over, supra note 1.

${ }^{6} \mathrm{Id}$.

${ }^{7}$ Id.

${ }^{8}$ John August \& Craig Mazin, Ep. 14: How Residuals Work-Transcript, JoHnAuguST.COM (Nov. 30, 2011), http://johnaugust.com/2011/scriptnotes-ep-14-how-residuals-work-transcript.

${ }^{9}$ WGA Contract 2007 Proposals, WRITERS GUILD OF AMERICA, http://www.wga.org/contract_07/proposalsfull2.pdf (last visited Oct. 29, 2012).

${ }_{10}^{10}$ August \& Mazin, supra note 8.

${ }^{11} I d$.

${ }^{12} I d$.
} 
that movie or television show get three cents. The retailer gets part of that money, but the remainder, a very large percentage, goes back to the studios which are profiting handsomely. ${ }^{13}$

The DVD has been boon for the film industry. In April 2004, the New York Times reported that while there had been $\$ 1.78$ billion in box office receipts from January to midMarch of that year, the companies made $\$ 4.8$ billion in home video. ${ }^{14}$ Yet the gains to the studio were deeper. The ubiquity of DVD players and DVDs allowed studios to market and strategize for DVD releases the same way that they market and strategize box office releases. By timing the DVD release of Kill Bill: Vol. 1 a few days before the theatrical release of Kill Bill: Vol. 2, Miramax made $\$ 40$ million in DVD sales the first day of release. ${ }^{15}$ DVDs also allowed the resurrection of cancelled television shows such as Arrested Development and Family Guy as well as enabled independent and art-house movies such as Donnie Darko to be re-released in theaters. ${ }^{16}$ Yet despite all this, writers' residuals were still governed by an antiquated Minimum Basic Agreement (MBA) which had been intended for a far less lucrative VHS industry.

\section{RESIDUALS AND COPYRIGHT}

The collective bargaining agreement between the WGA and the movie studios ensures residuals to writers. ${ }^{17}$ "Screenwriters ... sell the 'authorship' of their screenplays to the studios, and allow themselves to be classified as employees. Original works would thus become worksmade-for-hire."18 The copyright then belongs to the studio instead of the writer. The

\footnotetext{
${ }^{13} I d$.

${ }^{14}$ Sharon Waxman, Studios Rush To Cash In On DVD Boom; Swelling Demand for Disks Alters Hollywood's Arithmetic, N.Y. TIMES, Apr. 20, 2004, available at http://www.nytimes.com/2004/04/20/movies/studios-rush-cashdvd-boom-swelling-demand-for-disks-alters-hollywood-s.html?pagewanted=all\&src=pm.

${ }^{15} I d$.

${ }^{16} I d$.

${ }^{17}$ John August, Why Writers Get Residuals, JoHnAugust.COM (Nov. 11, 2007), http://johnaugust.com/2007/whywriters-get-residuals.

${ }^{18} I d$.
} 
compromise is that writers get residual payments for the reuse of what they had independently created. Moreover, by being classified as employees, they gain the ability to unionize in the form of the WGA. This brokered compromise allows production companies to perform the necessary changes to a script prior to arriving at a finished film or television show. Had this not been the case and writers retained their copyrights, editing scripts in the process of creating a movie would be a logistical nightmare. It is imperative that producers have the necessary flexibility to finish a film without having to discuss every minor change with a writer. Residuals, then, are an extremely important method of payment to the writers, who feel that these residuals are an appropriate part of the compensation package for creating a screenplay. Without them, the process "of authorship-transference ceases to be mutually beneficial."19

Given the importance of residuals and the screenwriters' belief that they were not being fairly compensated through the residual system, the writers' strike of 2007-2008 was, not surprisingly, a rehashing of many of the same issues as the 1985 strike, with a focus on new technology and a conviction by the writers to avoid being fooled yet again. Streaming internet, the new frontier of television and film consumption, had the potential to be worth billions of dollars in residual pay to writers, yet was paying out very little. Through the internet, content can be streamed in a variety of ways, all of which can affect payment to the writers. For shows that were free to watch with commercial interruption, writers did not receive a single penny of residual compensation. Thus, television shows which were streamed in this fashion through network websites or third party platforms, such as Hulu, left the writers completely

\footnotetext{
${ }^{19} I d$.
} 
uncompensated. ${ }^{20}$ However, when the viewer purchases the content via the internet, the studios were paying the same 0.3 percent that had been the case with home video residuals. ${ }^{21}$

The writers proposed that the home video residual formula (which applies to DVDs) be doubled to 0.6 percent and proposed that the re-use of all television and theatrical content over the internet, regardless of whether it is commercialized or not, earn writers a residual payment of 2.5 percent of the distributor's gross. ${ }^{22}$ Yet, it was the new media which became the centerpiece of the strike. While DVDs were already well established by 2007, the prevalence of streaming video was expanding rapidly. Netflix and Hulu had already become established as a means to watch residual media and Apple was beginning to enter the television and movie market as well. ${ }^{23}$ Ensuring that the writers were not left in the dark on this new and seemingly limitless avenue for residuals was of the utmost importance for the WGA.

Ironically, the strike was a godsend for Netflix, one of the corporations which had begun to profit through the rebroadcast of media. ${ }^{24}$ While writers were striking to ensure proceeds from television and movie re-use on platforms such as Netflix, viewers who no longer could enjoy new television shows due to the shut-down turned to Netflix DVDs. A USA TODAY/Gallup poll indicated that 49 percent of people were more likely to watch re-runs. ${ }^{25}$ Netflix was the fortuitous benefactor of the shut down. Perhaps not coincidentally, then, it was during the strike itself that Netflix massively expanded their business model. In January 2008, Netflix announced that it would begin allowing unlimited downloads of its online library of over 6000 movies for

\footnotetext{
${ }^{20}$ WGA Contract 2007 Proposals, supra note 9.

${ }^{21} I d$.

${ }^{22} I d$.

${ }^{23}$ Melissa Wilson, Netflix, Downloading, and the WGA Strike, FIREFOX NEWS (Jan. 17, 2008), http://firefox.org/news/articles/1082/1/Netflix-Downloading-and-the-WGA-Strike/Page1.html.

${ }^{24}$ Katie Hafner, A Lucky Strike for Netflix?, BITS BLOG - N.Y. TIMES (Jan. 3, 2008, 7:31 AM), http://bits.blogs.nytimes.com/2008/01/03/a-lucky-strike-for-netflix/.

${ }^{25}$ Gary Levin, Poll: Viewers Side With Striking Writers, USATODAY, Dec. 19, 2007, available at http://usatoday30.usatoday.com/life/television/news/2007-12-18-strike-poll_N.htm.
} 
all customers except those in the lowest payment range. ${ }^{26}$ This was a change from their previous structure which restricted the number of downloads that customers could enjoy. It also illustrated exactly what the writers were insisting all along - the internet is changing the way that movies and television are consumed and without significant changes to the MBA the writers would again be the ones who are hurt.

However, broadcast television refused to grind to a halt. Without exception, the networks increased the development of unscripted, or "reality," television. ${ }^{27}$ With no writers necessary for the production of ABC's Wife Swap or NBC's Clash of the Choirs, the networks had a popular alternative to scripted sitcoms or dramas. ${ }^{28}$ Reality television was, in a sense, the "ace up the sleeve" for the networks, as it not only helped to buoy profits during the period of writer inactivity, but also helped to marginalize the necessity of the writers at all. ${ }^{29}$ Unlike the work stoppages in the 1980s, where the networks relied on niche programming such as Cops and America's Most Wanted, the networks had already-established and popular programs to fill in where scripted television had been. ${ }^{30}$ Former NBC vice-president Warren Littlefield explained that "[t]here was a sense of powerlessness of having your product stream absolutely dry up. At some point you say, 'We don't want to be in this situation again,' and you start to build alternatives. That process takes time."31 Shows such as Survivor or American Idol were so tremendously lucrative that the writers had less power. This has not changed in the past few

\footnotetext{
${ }^{26}$ Wilson, supra note 23; Chris Kornelis, What to Do During the Writers' Strike, Vol. 15: Unlimited Netflix, SEATTLE WeEKLY BlOGS (Jan. 13, 2008, 1:29 PM), http://blogs.seattleweekly.com/threadcount/2008/01/what_to_do_during_the_writers_13.php.

${ }^{27}$ Christopher Rocchio \& Steve Rogers, Writers Strike Begins, Heavy Slate of Unscripted Shows Expected, REALITY TV WORLD (Nov. 5, 2007), http://www.realitytvworld.com/news/writers-guild-strike-begins-heavy-slate-ofunscripted-shows-expected-6038.php.

${ }^{28} I d$.

${ }^{29}$ Drew Grant, 10 Year Time Capsule: When Reality TV Took Over, SALON (Apr. 26, 2011, 2:45 PM), http://www.salon.com/2011/04/26/10_year_time_capsule_writers_strike/.

${ }^{30}$ Rocchio \& Rogers, supra note 27.

${ }^{31} I d$.
} 
years as five of the top nine weekly broadcasts for the 2010-2011 season were reality

television. $^{32}$

\section{A Successful Failing: After the Strike}

Initial reactions to the agreement which ended the 2007-2008 strike appeared optimistic for the writers. Although they received no increase in payments arising out of DVD sales (the rate stayed at 0.3 percent), they were given jurisdiction over new media and residual formulas based on gross revenue and not gross profit — meaning the writers would receive residuals on all proceeds from the internet and any unforeseen new mediums. ${ }^{33}$ This agreement was apparently enough for the writers, who learned from a very early point in negotiations that changes to the DVD residual scheme were not on the table. ${ }^{34}$ Studios claimed that increased marketing costs, which are tied to DVD releases, did not allow for a greater residual percentage for the writers. ${ }^{35}$ Despite this, 92.5 percent of writers voted to end the strike. This was greater than the 90 percent of writers who voted in favor of its authorization. ${ }^{36}$

Now, more than four years after the cessation of the strike, there are some data and perspective for what has occurred financially from the adjustments to the residual compensation scheme. Results are mixed. "Feature film residuals dropped $10 \%$, led by dramatic declines in

\footnotetext{
${ }^{32}$ Nellie Andreeva, Full 2010-2011 TV Season Series Rankings, DeADline HollywoOd (May 27, 2011, 10:56 AM), http://www.deadline.com/2011/05/full-2010-11-season-series-rankers/.

${ }^{33}$ Nikki Finke, STRIKE OVER: Hollywood Back to Work!, DEADLINE Hollywood (Feb. 12, 2008, 4:24 PM), http://www.deadline.com/2008/02/strike-end-game-wga-members-vote/; John August, The Deal, JoHNAUGUST.COM (Feb. 9, 2008), http://johnaugust.com/2008/the-deal.

${ }^{34}$ August, The Deal, supra note 33.

${ }^{35}$ Richard Verrier, Writers Guild Votes $90 \%$ in Favor of Strike, L.A. TIMES, Oct. 20, 2007, available at http://articles.latimes.com/2007/oct/20/business/fi-ballot20.

${ }^{36} I d$.
} 
receipts writers collected from DVD and Blu-ray disc sales."37 However, "[d]igital distribution by such online services as Netflix Inc. and Amazon.com was a bright spot for film. Fees paid to writers for new-media uses nearly tripled from 2010 to 2011 , growing to $\$ 3.37$ million.” 38 Despite this, during the last two years, there was a 20 percent decrease overall in the aggregate amount of money given to writers. ${ }^{39}$

Indeed, in the four years since the end of the strike, the situation for screenwriters has gotten worse than might have been anticipated. While negotiated gains gave the writers a piece of a pie that they greatly coveted, other challenges have vastly overshadowed these perceived gains. The concessions by the companies in regard to new media were undoubtedly a significant step which ameliorated writers' fears of being duped as they once were with home video. ${ }^{40}$ "But while these gains were made, the top priorities of previous contract talks, like creative rights, have slowly been undercut." 41 The result is a vastly more challenging, indeed perhaps subversive, payment structure which has become common, despite its apparent illegality.

\section{Work Without PAy - The NeW Model For Writers}

Studios have shifted their business model, creating fewer movies, more of which are sequels and remakes. This leaves fewer opportunities for independent films, filmmakers, and writers who are trying to make inroads into the industry. Thus, with less work and fewer opportunities, writers are more willing to let studios circumvent the collectively bargained

\footnotetext{
${ }^{37}$ Dawn C. Chmielewski, Film Jobs for Screenwriters Fall For Second Year, L.A. TIMES, July 2, 2012, available at http://www.latimes.com/entertainment/envelope/cotown/la-et-ct-writers-guild-employment20120702,0,968982.story.

${ }^{38} I d$.

${ }^{39} I d$.

${ }^{40}$ Tatiana Siegel, Studios Pose Obstacles For Writers, VARIETY (Feb. 8, 2008, 1:53 PM), http://www.variety.com/article/VR1117980524?refCatId=2821

${ }^{41} I d$.
} 
minimums for screenplays, rewrites, and polished products. ${ }^{42}$ The hope for them is that by being the good soldier in their initial opportunity, they will avoid being frozen out of potential future jobs from one of the "seven places to sell" (describing the seven major studios). ${ }^{43}$ Studios, it seems, have managed to work the system in their favor by creating an even more narrow way for writers to make careers in the field.

The process for purchasing a screenplay and compensating a writer is complex and tiered. The WGA sets minimums that writers are supposed to receive for each step of the writing process. For the year spanning from May 2, 2012 to May 1, 2013, a screenwriter is guaranteed a minimum of $\$ 65,013$ for an original screenplay, including treatment - the storyboard process which is usually the first way that a screenplay is pitched to a production company. ${ }^{44}$ Yet the process is neither this simple nor finished at this juncture. The $\$ 65,013$ is broken into three payment installments: the original treatment, the first draft, and the final draft. ${ }^{45}$ The original treatment, when an idea and storyboard is first proposed, is to be paid a minimum of $\$ 29,457 .{ }^{46}$ The first draft delivers a minimum of another $\$ 25,601$ and the final draft yet another payment of $\$ 9,955$, totaling the $\$ 65,013$ payment. ${ }^{47}$ However, upon the delivery of this final draft, a studio can ask for a rewrite. The fee for this is supposed to be $\$ 21,332$ and above. ${ }^{48}$ A final polish to a screenplay is supposed to deliver the writer a minimum of $\$ 10,673 .{ }^{49}$ Each of these rewrites and polishes are known as "steps" in the screenwriting industry. Yet, despite having collectively

\footnotetext{
${ }^{42} I d$.

${ }^{43}$ Id. 29, 2012).

${ }^{45}$ Id. supra note 44.

${ }^{47}$ Schedule of Minimums, supra note 44.

${ }^{48} \mathrm{Id}$.

${ }^{49} I d$.
}

${ }^{44}$ Schedule of Minimums: Writers Guild of American 2011 Theatrical and Television Basic Agreement, WRITERS GUILD OF AMERICA, http://www.wga.org/uploadedFiles/writers_resources/contracts/min2011.pdf (last visited Oct.

${ }^{46}$ How to Write a Film Treatment, LiGHTS FILM SCHOOL, http://www.lightsfilmschool.com/articles/treatments/index.html (last visited Oct 29, 2012); Schedule of Minimums, 
bargained for this process and despite having it be explicitly detailed, studios are failing to honor this payment structure more and more frequently. ${ }^{50}$

A survey of 743 WGA screenwriters, conducted from February 13, 2012 to March 5, 2012, shows the dreary nature of the industry. Seventy-two percent of writers felt that the industry is much worse for writers now than it once was, with the majority of the problems lying in the deteriorating compensation structure. ${ }^{51}$ Seventy percent of writers said that free rewrites were frequently the norm at major studios while 39 percent said that they had been paid late and 37 percent said that the studios actually thieved their idea. ${ }^{52}$ Writers have lamented that this last point has become more prevalent now that writers are being requested to detail plot twists and the intricacies of their ideas during the pitching process, which occurs early in the writing process. $^{53}$ Nearly 50 percent of writers said that they had personally been asked, typically by the producer or studio representative, to do an uncompensated rewrite. ${ }^{54}$ Backed into this corner, 51 percent of writers working for major studios provided the uncompensated rewrite because they felt it necessary in order to either keep their job or get hired in the future. ${ }^{55}$ With all these obvious violations of the WGA agreement, it is apparent why nearly three-quarters of the writers polled felt that employment in the industry had become more difficult.

An even more confounding shift in the movie industry for writers has been the contraction of the industry as a whole and the repetition of ideas which are being turned into

\footnotetext{
${ }^{50}$ Siegel, supra note 40.

${ }^{51}$ Writers Guild of America Screenwriter Survey, WRITERS GUILD OF AMERICA, http://www-deadlinecom.vimg.net/wp-content/uploads/2012/07/screensurvey_120724213715.pdf (last visited, Nov. 1, 2012) [hereinafter Writers Guild Survey].

${ }^{5}$ Id.

${ }^{53}$ Siegel, supra note 40.

${ }^{54}$ Writers Guild Survey, supra note 51.

${ }^{55} \mathrm{Id}$.
} 
films. Fewer movies are being made which results in fewer jobs for screenwriters. ${ }^{56}$ Whereas upwards of 1,500 films were produced annually by Hollywood in the 1970s, that number has gradually and consistently shrunk to 450 in $2010 .^{57}$ This, quite obviously, means less work and less pay. This contraction has led to 15 percent fewer writers working in film in 2012 than did in 2010 - a profound decrease for a mere two-year period. ${ }^{58}$ Worse yet, there is little reason to believe that this gradual contraction will cease.

Exacerbating these challenges for screenwriters, while fewer movies are being made, fewer yet are original ideas as major studios have become increasingly apt to capitalize on remakes, sequels and reboots of previous films with known characters. ${ }^{59}$ Former CFO of Disney admits that the major film studios "suffer from a great deal of inertia." 60 A humorous story highlighting this propensity for studios to morph new ideas into recycled premises involves David Marconi, a screenwriter who was commissioned to write an original movie treatment regarding cyber warfare called WW3.com. ${ }^{61}$ Marconi had enjoyed previous success as a screenwriter, having penned the 1998 film Enemy of the State. ${ }^{62}$ Yet, by the time it was released, the project had become Live Free or Die Hard, the fourth installment of Bruce Willis's John McClane franchise. ${ }^{63}$

\footnotetext{
${ }^{56}$ See Nikki Finke, WGA Screenwriter Survey: Scripters' Status “Significantly Deteriorated", DEADLINE HOLLYWOOD (July 24, 2012, 2:39 PM), http://www.deadline.com/2012/07/wga-screenwriter-survey-scripters-statussignificantly-deteriorated/; Film Producer: Odds of Getting In, SHMOOP, http://www.shmoop.com/careers/filmproducer/odds-of-getting-in.html (last visited Nov 1, 2012)

${ }^{57}$ Film Producer: Odds of Getting In, supra note 56.

${ }^{58}$ Chmielewski, supra note 37.

${ }^{59}$ Gregg Kilday, LAFF 2012: Cinedigm's Chris McGurk Predicts a Digital-Driven Indie Film Renaissance, THE HOLLYWOOD REPORTER (June 16, 2012, 12:21 PM), http://www.hollywoodreporter.com/news/laff-2012-cinedigmchris-mcgurk-digital-indie-renaissance-338473.

${ }^{60} I d$.

${ }^{61}$ Daniel Frankel, Play It Again, Fox: Stuck on Sequels, Remakes \& Reboots, THE WrAP, http://www.thewrap.com/movies/article/play-it-again-fox-stuck-sequels-remakes-reboots-21700?page=0,0 (last visited Nov. 1, 2012).

${ }^{62}$ Enemy of the State, INTERNET MOVIE DATABASE, http://www.imdb.com/title/tt0120660/ (last visited Nov. 1, 2012).

${ }^{63}$ Frankel, supra note 61.
} 
This situation is not rare, and it certainly is not an anomalous exception. From October 14, 2010 through the end of 2011, 20 ${ }^{\text {th }}$ Century Fox released fifteen movies, seven were sequels, remakes or reboots (called remakes hereafter) and eight were originals. ${ }^{64}$ During the same timeframe, Warner Brothers released a total of twenty-five films, fourteen of which were originals and the balance remakes. ${ }^{65}$ Disney released seven originals and rehashed seven remakes, with familiar characters from The Muppets, Winnie the Pooh, Cars 2, and a new Pirates of the Caribbean installment. ${ }^{66}$ Paramount was no different as only seven of their thirteen films were original concepts. ${ }^{67}$ Of the major studios, only Universal and Sony had at least three-quarters of their films be original. ${ }^{68}$

It is hard to draw any sort of causal effect from the writers' strike itself to the new trends in the industry. But even without this kind of connection, it is anecdotally obvious that although members of the WGA entered the strike of 2007 with intentions to demand what was rightfully theirs in an effort to bolster their earnings potential, the situation has worsened. From 2010 to 2012, there was a total 20 percent decrease in earned residuals, despite increases in revenue generated from Netflix and other online sources. ${ }^{69}$ This does not imply that the situation would have been better had the writers not gone on strike; it is possible that it would have actually been much worse. But by overplaying the importance of equal compensation of residuals, the writers may have overlooked an even more ominous signal on the horizon. The movie industry is contracting, leaving the same number of writers to vie for fewer spots with studios, who are more than willing to let the work-starved masses undercut each other for an opportunity.

\footnotetext{
${ }^{64}$ Originals vs. Rehashes: Studio by Studio, THE WRAP (Oct. 14, 2010), http://www.thewrap.com/movies/slideshow/originals-vs-rehashes-studio-studio-slideshow-21735.

${ }^{65} I d$.

${ }^{66} I d$.

${ }^{67} \mathrm{Id}$.

${ }^{68} \mathrm{Id}$.

${ }^{69}$ Chmielewski, supra note 37.
} 